\title{
Phenological Models of Flower Bud Stages and Fruit Growth of 'Montmorency' Sour Cherry Based on Growing Degree-day Accumulation
}

\author{
Costanza Zavalloni'1,3, Jeffrey A. Andresen'1, and J.A. Flore ${ }^{2}$ \\ Michigan State University, East Lansing, MI 48824
}

\begin{abstract}
AdDitional INDEX words. growth model, Prunus cerasus, phenology, fruit diameter, tart cherry
Abstract. A simulation model for determining flower bud phenological stages and fruit growth as a function of daily maximum and minimum temperatures was developed for 'Montmorency' sour cherry (Prunus cerasus L.). The models were developed and tested with observations collected in the three major sour cherry production areas in Michigan located in northwestern, western central, and southwestern sections of the lower peninsula. Observations of flower bud phenology and fruit diameter were collected at 3- to 7-day intervals, in spurs and terminal shoots across multiple years. Nonlinear equations using accumulation of growing degree-days (base $4^{\circ} \mathrm{C}$ ) as an independent variable were fitted to observed flower bud phenological stages and fruit diameter, expressed as percentage of final fruit diameter. Simulated bud phenology stages were in agreement with observed data. Mean differences of simulated vs. observed dates of early phenological stages in the three production areas were between 4 and 1 days for side green and near 0 days for tight cluster, while during later stages (e.g., first bloom and full bloom) mean differences ranged from -2 to 0 days. Means differences of predicted fruit diameter were in the range of 0 to -3 days. Needing only daily temperature data, these simulation models have potential applicability in improving the timing and efficiency of management decisions related to crop phenology, such as pest control, fertilization, and irrigation.
\end{abstract}

Michigan is the leading producer of sour cherry in the United States, accounting for approximately $70 \%(90,400 \mathrm{Mg})$ of the U.S. sour cherry production in the period 1995-2004 (National Agricultural Statistic Service, 2005). The main sour cherry production area in Michigan extends along the western side of the lower peninsula near Lake Michigan (Fig. 1). Three major production sub-areas are identified within the western edge of the state, including northwest, with about $50 \%$ of total production, and west-central and southwest, with $25 \%$ and $20 \%$ of the production, respectively (Michigan Department of Agriculture, 2005).

Knowledge and awareness of flower bud phenological stages and fruit growth development are important requirements for many facets of crop management. Phenological models, by informing farmers of crop growth and developmental stages during the growing season, can be useful tools for improving the efficacy and timing of pesticide applications, fertilization, irrigation, and in scheduling harvest operations (Chmielewski, 2003). Phenological models also can potentially have numerous economical and environmental benefits. For example, increasing the efficacy of pesticide sprays, by improving the timing of applications, could decrease the number of pesticide applications and ultimately reduce the cost of production. In addition, plant and crop phenology has recently become a key component of climate change impact research (Menzel,

Received for publication 21 July 2005. Accepted for publication 7 June 2006. The authors would like to thank Dr. Charlie Edson, Dr. Lynn Sage, Jim Nugent, Dr. Bill Shane, Dr. Mira Danilovich, and numerous growers for providing phenological observations. The authors would also like to thank Dr. Julie A. Winkler for critically reviewing an early version of the manuscript and Tracy Aichele for developing the Michigan map reported. This work was partially funded by the U.S. Environmental Protection Agency under project number R83081401-0. 'Department of Geography.

${ }^{2}$ Department of Horticulture.

${ }_{3}^{3}$ Corresponding author; e-mail address: Costanza.Zavalloni@ua.ac.be
2003). The timing of specific flower bud phenological stages can be used as a climatological indicator at the regional level and contribute to the evaluation of possible impacts of climate change and variability.

In order to overcome the endodormancy (also called rest period) in which growth is regulated by physiological factors inside the affected structure, deciduous fruit trees require a period of exposure to chilling temperatures (Weinberger, 1967). After the chilling requirement has been satisfied, trees enter the ecodormancy period where dormancy is imposed only by unfavorable environmental conditions (Lang etal., 1987). During ecodormancy, growth and development are resumed when temperatures are above a species-dependent threshold and after a certain amount

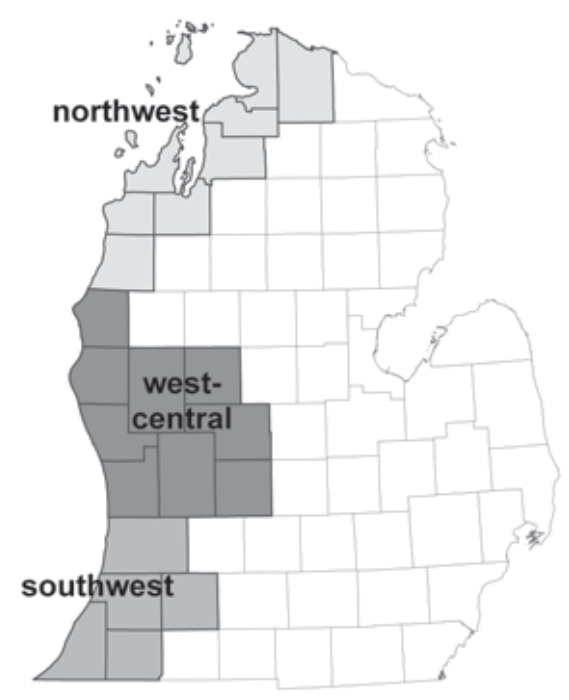

Fig. 1. Major sour cherry production areas in Michigan. 
of heat units is accumulated. The amount of heat or thermal time required to reach a specific stage of phenological development can be expressed in terms of either growing degree-hours (GDH), which are calculated as the sum of hours the temperature is at or above a given threshold, or growing degree-days (GDD), which are calculated similarly to GDH but with daily maximum and minimum temperatures. GDD have been successfully used for predicting bloom in almond (Prunus dulcis Mill.) (DegrandiHoffman et al., 1996), harvest dates in peach [Prunus persica (L.) Batsch] (Smith, 1985), completion of endodormancy in peach (Richardson et al., 1974), and leaf emergence and expansion in sour cherry (Eisensmith et al., 1980, 1982).

An earlier attempt to simulate sour cherry flower bud phenology with GDH accumulation was carried out by Anderson et al. (1986). Their approach included an adaptation of a generic deciduous tree fruit model (Richardson et al., 1975) to fit sour cherry flower bud growth stages, and spring growth and development were initiated only after chilling requirement was satisfied (Richardson et al., 1974). Validation of this simulation model included only first bloom and bloom phenological stages, and was limited to 2 years of observations from Michigan.

Fruit growth has been quantitatively described using several indices, such as volume in sour cherry (Tukey, 1934), fresh weight in sour cherry (Eisensmith et al., 1980) and apple (Malus domestica Borkh.) (Lakso et al., 1995), dry weight in peach (DeJong and Goudriaan, 1989), and fruit diameter in peach, apple, and sour cherry (Genard and Bruchou, 1993; Orlandini et al., 1999; Tukey, 1934). The development of sour cherry fruit has usually been divided into three stages, based on the fruit diameter growth. The first and third stages (Stages I and III, respectively) are characterized by a rapid enlargement of the fruit and are separated by a slow growing stage (Stage II), in which the stony pericarp differentiates and hardens (Tukey, 1934). For simplicity, most previous descriptions of sour cherry fruit growth in terms of fresh weight, volume, and diameter (e.g., Eisensmith et al., 1980; Tukey, 1934) were based on the number of calendar days after full bloom and not on accumulated GDD. Given the need for accurate phenological estimates, the dependence of crop phenology on temperature, and the large year-to-year variability of temperatures at a given location within a given growing season (e.g., Andresen and Harman, 1994), it is logical to express fruit development as a function of GDD accumulation to obtain a model suited for different locations.

The primary objective of this study was the development of a sour cherry phenology simulation model for 1) flower bud developmental stages and 2) fruit development, as function of accumulated GDD. Development of the models with GDH was not considered, as hourly temperatures data are frequently not available to farmers and crop managers.

\section{Materials and Methods}

The simulation models were developed and validated with observed data from the three major sour cherry growing regions in Michigan (Fig. 1).

Flower bUd PHENOLOGY MODEL DEVELOPMENT. Detailed phenological observations of flower bud development were made in three sour cherry orchards of mature 'Montmorency' grafted on 'Mahaleb' in 1994 and 1995. The three orchards were located at the Clarksville Horticultural Experimental Research Station near Clarksville in west-central Michigan (lat. $42^{\circ} 52^{\prime} 12^{\prime} \mathrm{N}$, long. $85^{\circ} 15^{\prime} 36^{\prime} \mathrm{W}$, elevation $273 \mathrm{~m}$ ), at a commercial orchard near Eau Claire in southwestern Michigan (lat. $42^{\circ} 04^{\prime} 48^{\prime} \mathrm{N}$, long. $86^{\circ} 21^{\prime} 36^{\prime} \mathrm{W}$, elevation $220 \mathrm{~m}$ ), and at the Northwest Horticulture Experimental Station near Traverse City in northwestern Michigan (lat. $44^{\circ} 52^{\prime} 48^{\prime} \mathrm{N}$, long. 85 $40^{\prime} 48^{\prime} \mathrm{W}$, elevation $247 \mathrm{~m}$ ). At the northwestern location, phenological observations were collected only during 1994. Five trees were randomly selected among those with similar canopies and vigor in each orchard. In each of the five trees, flower bud phenology was recorded twice per week in four random shoots and spurs per tree, selected in the south, north, west, and east quadrants of the canopy. Observations of flower bud developmental stages were taken following the guidelines of Dennis and Howell (1974). In order to account for variability within a spur or a shoot, all the flowers in the selected spur or shoot were evaluated and the average stage of flower bud development was recorded.

Daily minimum and maximum temperatures were used to calculate GDD using the Baskerville and Emin method (Baskerville and Emin, 1969), which approximates the continuous diurnal temperature pattern on a given day with a sine wave. A base temperature of $4{ }^{\circ} \mathrm{C}$ was selected based on the earlier work of Eisensmith et al. (1980, 1982), who determined a base threshold for sour cherry vegetative growth using phenological observations from Michigan and Wisconsin. Representative daily weather data to calculate GDD were acquired from weather stations located at the Clarksville Horticulture Experimental Station and the Northwest Michigan Horticulture Research Station, while data for Eau Claire were acquired from a National Oceanic and Atmospheric Administration (NOAA) cooperative climatological observation site, located in a very similar commercial orchard setting, $10 \mathrm{~km}$ southeast of the orchard where the phenological observations were collected (NOAA, 1995, 1997).

The first clearly identifiable flower bud developmental stage, side green (stage 2), was used as a biofix for the onset of growth, with GDD accumulated starting 1 Mar., a date selected as an approximation of the earliest beginning of development across the study area (earliest observed side green in our dataset was 28 Mar. 2000, in the southwestern region). In order to determine the occurrence of side green, approximately half of the historical values of side green in the period 1987-2003 were averaged (total of 20 observations, considering even years for the southwestern region and odd years for both the western central and northwestern areas). The other half of the historical records for side green was used for the validation of the model. The flower bud phenological model was developed using nonlinear regression [PROC NLIN (SAS version 8; SAS Institute, Cary, N.C.)]. The function was derived using accumulated GDD as the independent variable and the following phenological stages, from side green, as dependent variable: green tip (stage 3), tight cluster (stage 4), open cluster (stage 5), first white (stage 6), first bloom (stage 7), full bloom (stage 8), and petal fall (stage 9). Data used to generate the flower bud phenology predictive model included growing season observations from 1994 at Eau Claire and Traverse City, and 1994 and 1995 at Clarksville.

Flower bUd PHENOLOGY MODEl VAlidation. The flower bud model was validated using historical observations from the three major sour cherry production areas in Michigan: southwestern lower Michigan for the period 1980-2003, west-central Michigan for the period 1987-2003, and northwestern lower Michigan for the period 1983-2003. The observations were taken by Michigan State University Extension and Michigan 
Agricultural Experiment Station personnel each season from a variety of commercial and research orchards in the regions of interest. Model goodness of fit was determined by comparing the simulated dates of different phenological stages with the observed dates in terms of mean (ME) and mean absolute error (MAE), defined as the mean absolute difference of the simulated and observed dates. Weather data used to calculate the "district" GDD were acquired from NOAA cooperative climatological observation network sites (NOAA, 2004) representative of the three main sour cherry growing areas: Benton Harbor (southwestern Michigan), Montague (west-central Michigan), and Maple City (northwestern Michigan).

Fruit Growth MODEL DEVELOPMENT. Fruit diameter observations (20 fruits per shoot type, location, and sampling time) were recorded every 2 to $7 \mathrm{~d}$ in the same orchards and with similar sampling procedures to those described for the flower bud phenological observation data. Fruit diameter was selected for modeling fruit growth because it is a non-destructive measurement and can be easily assessed in the field at the time of measurement. Data from 1994 for Eau Claire, Clarksville, and Northwest Michigan Horticulture Research Station were used to develop the fruit growth model using a nonlinear regression procedure as reported above. Fruit diameter observations were also collected in 2004 in a 15-year-old commercial orchard located in Belding in west-central Michigan (lat. $43^{\circ} 06^{\prime} 36^{\prime} \mathrm{N}$, long. $85^{\circ} 18^{\prime} 36^{\prime} \mathrm{W}$, elevation $257 \mathrm{~m}$ ) to obtain additional data for validation of the model.

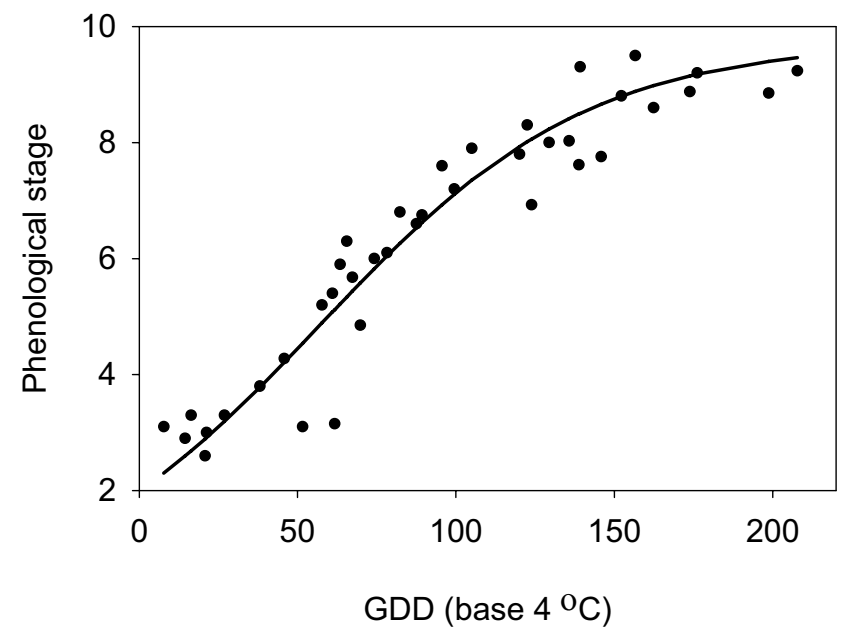

Fig. 2. Phenological stages of sour cherry flower bud development as a function of growing degree-day [GDD (base $4^{\circ} \mathrm{C}$ )] accumulation from side green (stage 2). Data used to generate the flower bud phenology simulation model includes 1994 at Eau Claire, Mich., and Traverse City, Mich., and 1994 and 1995 at Clarksville, Mich. Each point represent the mean of 40 replicates of stage of flower bud development observed in spur and shoot of sour cherry tree. The solid line depicts the fitted logistic model.
Fruit Growth MODEL VALIDATION. The fruit development simulation model was validated using observations from 1995 for Eau Claire and Clarksville, and from 2004 for Belding. Weather observations to calculate GDD were acquired for Eau Claire and Clarksville from weather stations described in the flower bud development model section. Weather data for Belding were obtained from an automated weather station within the Michigan Automated Weather Network (2005), located 2 km east of the orchard.

\section{Results}

Observations collected on the south, north, west, and east quadrants of the trees were analyzed by shoot type (spur or terminal shoot). No significant differences were observed among the canopy quadrants across the different dates. Analysis of variance (ANOVA) on phenological stages and fruit diameter observations recorded on spur and terminal shoots showed no statistical differences; therefore, observations from spurs and terminal shoots were averaged at each sampling date.

Flower BUd PHENOLOGY MODEL DEVELOPMENT. Based on the historical observations from the three sour cherry production areas, the side green stage was determined to occur at 120 GDD from 1 Mar. All remaining flower bud stages were defined as GDD accumulations starting from side green. A logistic function was fitted to the flower bud phenological stages from side green as a function of accumulated GDD:

$$
\mathrm{y}=\frac{\mathrm{k}}{1+\left[\left(\mathrm{k}-\mathrm{n}_{0}\right) / \mathrm{n}_{0}\right] \exp ^{-\mathrm{r} \cdot \mathrm{GDD}}}
$$

where $\mathrm{y}=$ flower bud phenological stage, GDD = growing degree-days (base $4{ }^{\circ} \mathrm{C}$ ) accumulated from side green, and $\mathrm{n}_{0}=2$ (Fig. 2). Empirical factors $\mathrm{k}$ and $\mathrm{r}$, their standard error (SE), and 95\% confidence intervals of the fitted logistic function are given in Table 1 . There was a high correlation $\left(\mathrm{R}^{2}=0.992\right)$ between phenological stage and GDD. Using the fitted model it was possible to determine the sum of GDD required for the remaining bud phenological stages from side green (Table 2).

FLOWER BUD PHENOLOGY MODEL VALIDATION. Simulated bud phenological stages from the southwestern, western central, and northwestern regions were in good agreement with observed data (Fig. 3, Table 3). MAE of simulated vs. observed dates of early phenological stages in the southwestern region were 4 and $2 \mathrm{~d}$ for side green and tight cluster, respectively, and in the range of 3 to $4 \mathrm{~d}$ for later stages (e.g., first bloom and full bloom; Table 3). Similar results were obtained for early phenological stages in the west-central and northwestern production areas of Michigan. Mean differences of more advanced phenological stages generally ranged from 2 to $3 \mathrm{~d}$ in the western central region and 1 to $2 \mathrm{~d}$ in the northwestern region (Table 3). Mean differences between

Table 1. Regression analysis of sour cherry flower bud phenological model from stage 3 through stage 9 in relation to growing degree-day (base $4{ }^{\circ} \mathrm{C}$ ) accumulated from stage 2 (side green).

\begin{tabular}{|c|c|c|c|c|c|c|c|c|c|}
\hline \multirow[b]{2}{*}{ Parameter } & \multirow[b]{2}{*}{ Estimate } & \multirow[b]{2}{*}{$\mathrm{SE}$} & \multirow[b]{2}{*}{$\begin{array}{c}95 \% \text { Confidence } \\
\text { intervals }\end{array}$} & \multirow[b]{2}{*}{$\mathrm{R}^{2}$} & \multicolumn{4}{|c|}{ ANOVA } & \multirow[b]{2}{*}{$P$} \\
\hline & & & & & Source & $\mathrm{df}$ & $\begin{array}{l}\text { Sum of } \\
\text { squares }\end{array}$ & $\begin{array}{l}\text { Mean } \\
\text { square }\end{array}$ & \\
\hline $\mathrm{k}$ & 9.7329 & 0.2673 & 9.1930 to 10.2727 & $0.992^{z}$ & Regression & 2 & 2123 & 1061.7 & $<0.0001$ \\
\hline $\mathrm{r}$ & 0.0236 & 0.00113 & 0.0213 to 0.0258 & & Residual & 41 & 16.2045 & 0.3952 & \\
\hline
\end{tabular}

${ }^{2} \mathrm{R}^{2}=1-\Sigma\left(\mathrm{y}_{\mathrm{i}}-\hat{\mathrm{y}}_{\mathrm{i}}\right)^{2} / \Sigma\left(\mathrm{y}_{\mathrm{i}}-\mathrm{y}\right)^{2}$ where $\mathrm{y}_{\mathrm{i}}$ and $\hat{\mathrm{y}}_{\mathrm{i}}$ are the observed and estimated values, respectively, and $\mathrm{y}$ is the arithmetic mean of the observed values (Kvålseth, 1985). 
Table 2. Phenological stages of sour cherry flower bud and number of growing degree-days $\left[\mathrm{GDD}\right.$ (base $\left.\left.4{ }^{\circ} \mathrm{C}\right)\right]$ necessary to reach the specific phenological stages determined with the sour cherry phenological model. Sum of GDD for the different phenological stages were calculated starting accumulation of GDD from side green.

\begin{tabular}{lc}
\hline Phenological stage & GDD \\
\hline 3. Green tip & 24 \\
4. Tight cluster & 44 \\
5. Open cluster & 60 \\
6. First white & 78 \\
7. First bloom & 98 \\
8. Full bloom & 123 \\
9. Petal fall & 181 \\
\hline
\end{tabular}

simulated and observed dates of most of the stages in the northwestern region were equal to $0 \mathrm{~d}$, indicating an absence of bias in the model predictions (Table 3). Linear regression analysis was performed on dates of predicted vs. observed bud phenological stages to closely evaluate possible bias of the phenological model (Fig. 3). Overall, there was a very good relationship between observed and simulated phenological stages, with the highest coefficient of determination in the northwestern and western central regions $\left(\mathrm{R}^{2}=0.934\right.$ and $\mathrm{R}^{2}=0.925$, respectively). Results from a Z-test for slope $=1$ and intercept $=0$ suggested that the slopes were not significantly different than 1 and the intercepts not significantly different than 0 at the $95 \%$ confidence level for the northwestern region (Fig. 3C), confirming the absence of bias. The Z-test results for slope and intercept of the linear regression were somewhat different for western central and southwestern regions, indicating both that the slopes were different than 1 and the intercepts different than 0 at a 95\% confidence level (Fig. 3A-B). In both of the latter cases, the models tended to over-predict the early stages of flower bud phenology and under-predict the later stages of development, as evidenced by positive intercepts and slope values slightly less than 1.0 (Fig. 3A-B).

Fruit growth model DeVelopment. A double-sigmoid prediction function of the form

$$
y=\frac{B_{0}}{1+\exp \left[-\left(B_{1}+B_{2} x+B_{3} x^{2}+B_{4} x^{3}\right)\right]}
$$

was fitted to the fruit diameter observations expressed as percentage of final fruit size, with $y=$ fruit diameter (percentage of final diameter), $\mathrm{x}=$ accumulated GDD (base $4{ }^{\circ} \mathrm{C}$ ) beginning at full bloom, and $\mathrm{B}_{0}=100$ (Fig. 4). Empirical constants $\mathrm{B}_{1}, \mathrm{~B}_{2}, \mathrm{~B}_{3}, \mathrm{~B}_{4}$, constant SE, and $95 \%$ confidence intervals of the fitted doublesigmoid function are given in Table 4. Overall, the double-sigmoid fitted function was found to describe fairly well $\left(\mathrm{R}^{2}=0.936\right)$ the relationship between fruit size and GDD.

Fruit GRowth MOdel VALIDATION. The fruit diameter observations, collected in Clarksville, Eau Claire, and Belding and expressed as percentage of final fruit size, were compared with simulated values by the fruit growth model (Table 5). Overall, MAE between simulated and observed dates of similar fruit size were in the range of 2 to $4 \mathrm{~d}$ (Table 5). Mean fruit diameter differences of $0 \mathrm{~d}$ were obtained at Eau Claire and Belding, while a value of $-3 \mathrm{~d}$ at Clarksville suggested a tendency to overestimate fruit size (Table 5). A scatterplot of predicted vs. observed percentage of fruit diameter comparing the same dates of observed and predicted values is given in Fig. 5. The close fit with the 1:1 line and the high coefficient of determination

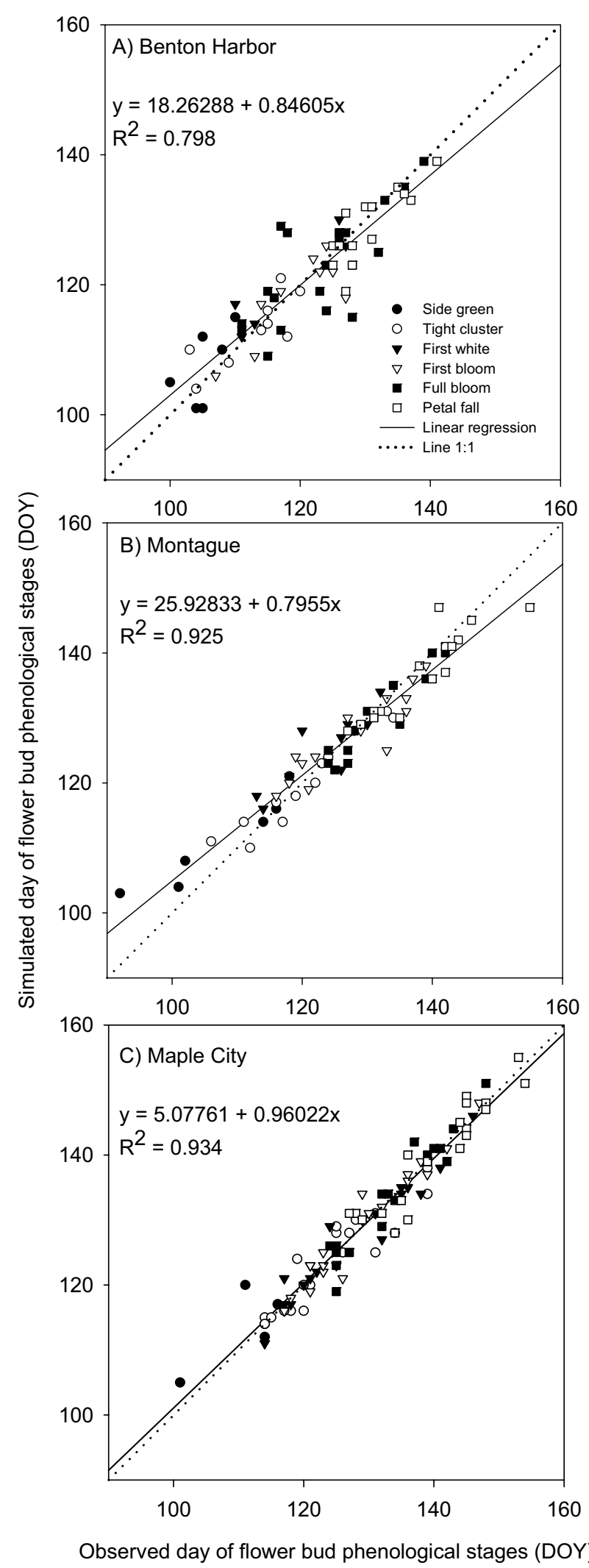

Fig. 3. Simulated vs. observed dates of flower bud phenological stages of sour cherry. The model was tested using weather observations from the following location in Michigan: (A) Benton Harbor (southwest), (B) Montague (west-central), and (C) Maple City (northwest). Each point represents the calendar day of the year (DOY) for a given observed/simulated phenological stage. Phenological observations for southwest are relative to the period 1980-2003, for west-central to the period 1987-2003, and for northwest to the period 1983-2003. 
Table 3. Statistical differences between observed and predicted flower bud phenological observations of sour cherry in three main production areas of Michigan: southwest (period 1980-2003), west-central (period 1987-2003), and northwest (period 1983-2003).

\begin{tabular}{llccc}
\hline $\begin{array}{l}\text { Michigan } \\
\text { location }\end{array}$ & $\begin{array}{l}\text { Phenological } \\
\text { stagez }\end{array}$ & $\begin{array}{c}\text { Time of } \\
\text { observation } \\
\text { (years) }\end{array}$ & $\begin{array}{c}\text { Mean } \\
\text { difference } \\
\text { Southwest }\end{array}$ & $\begin{array}{c}\text { MAEy } \\
\text { (d) }\end{array}$ \\
& 2. Side green & 6 & 2 & 4 \\
& 4. Tight cluster & 9 & 0 & 2 \\
& 6. First white & 5 & 2 & 3 \\
& 7. First bloom & 9 & -1 & 3 \\
& 8. Full bloom & 21 & 0 & 4 \\
West-central & 9. Petal fall & 16 & -2 & 3 \\
& 2. Side green & 6 & 4 & 4 \\
& 3. Green tip & 9 & 4 & 4 \\
& 4. Tight cluster & 12 & 0 & 2 \\
& 5. Open cluster & 7 & 0 & 2 \\
& 6. First white & 9 & 2 & 3 \\
& 7. First bloom & 15 & 0 & 3 \\
& 8. Full bloom & 14 & -2 & 2 \\
& 9. Petal fall & 15 & -2 & 2 \\
Northwest & 2. Side green & 6 & 1 & 4 \\
& 4. Tight cluster & 19 & 0 & 2 \\
& 6. First white & 18 & 0 & 2 \\
& 7. First bloom & 19 & 0 & 1 \\
& 8. Full bloom & 19 & 0 & 2 \\
& 9. Petal fall & 19 & 0 & 2 \\
\hline
\end{tabular}

${ }^{z}$ Weather observations utilized to simulate phenological stages were taken from the following location in Michigan: Benton Harbor (southwest), Montague (west-central), and Maple City (northwest).

yMean absolute error (MAE) is defined as the difference between the absolute value of predicted minus observed.

$\left(\mathrm{R}^{2}=0.97\right)$ confirmed a satisfactory model fit. Results from the Z-test of the regression analysis indicated that the slope was not significantly different than 1 and the intercept not significantly different than 0 , at $95 \%$ confidence level, even given a small departure of the model estimates from the 1:1 line in late stages of fruit development (sizes between $60 \%$ and $100 \%$ of total).

\section{Discussion}

The flower bud phenological simulation model developed in this study correlates well with the observations collected in different years and locations in Michigan. Moreover, the sensitivity analysis performed in the three sour cherry growing regions over a relatively long period of time (15 to 20 years), and during both early and late stages of flower bud development demonstrates the overall accuracy and robustness of the model.

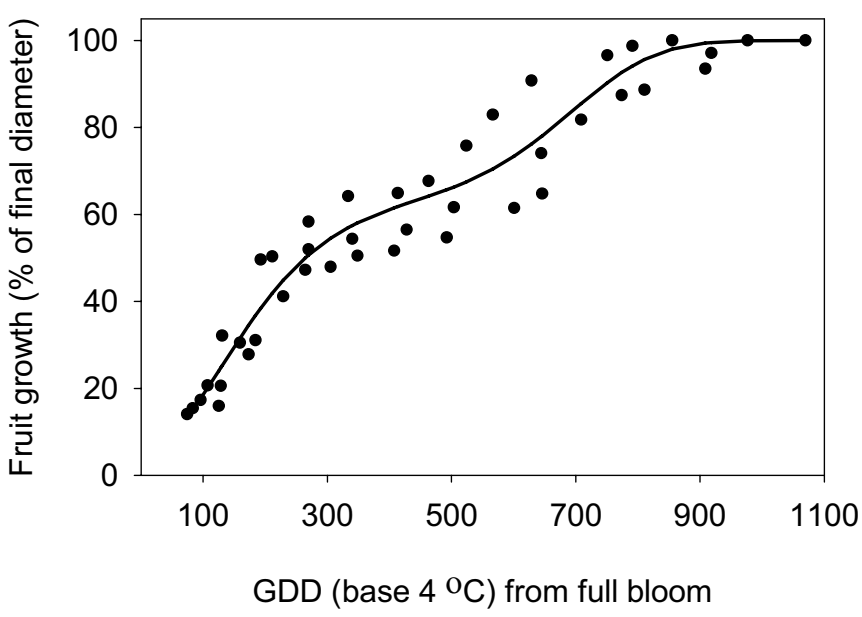

Fig. 4. Sour cherry fruit growth as a function of growing degree-day [GDD (base $\left.4{ }^{\circ} \mathrm{C}\right)$ ] accumulation from full bloom. Data from 1994 for Eau Claire, Mich., Clarksville, Mich., and Northwest Michigan Horticulture Research Station were used to develop the fruit growth function. Each point represents the mean of 40 replicates of fruit diameter, expressed as percentage of final fruit size, observed in spur and shoot of sour cherry tree. The solid line depicts the fitted double-sigmoid function.

For a reference comparison, when observed and predicted calendar dates of flower bud development stages were compared, $\mathrm{ME}$ and MAE ranged from -7 to $5 \mathrm{~d}$ and 3 to $9 \mathrm{~d}$, respectively (data not shown). Initially, an attempt was made to set the beginning of flower bud development conditional on the completion of chilling requirements estimated with the a model proposed by Richardson et al., (1974), hereafter referred to as the Utah model. In order to overcome the endodormancy stage and resume growth, sour cherry needs to be exposed to 954 chilling hours (Anderson et al., 1986; Richardson et al., 1974). In an initial test with approximately 20 years of data, the Utah model was found to be inaccurate under Michigan conditions, especially in the western central and southwestern regions, where the model consistently tended to delay the seasonal onset of growth (data not shown). Unfortunately, detailed information on completion of rest and budbreak at the three major Michigan sour cherry production areas was not available to attempt the modeling of rest requirement and end of dormancy. Following investigation of the relationship between early bud stages and accumulated GDD with Michigan observations, a relatively consistent relationship was found between GDD accumulation from a fixed calendar date and the timing of early bud development stages, so a decision was made to biofix on the early-season side green stage. Phenological stages have been successfully used as a biofix in apple models for the onset of growth of shoot and fruit (Edson, 1986) and for monitoring insect development (Gage et al., 1982).

Table 4. Regression analysis for sour cherry fruit diameter in relation to growing degree-days (base $4{ }^{\circ} \mathrm{C}$ ) accumulated from full bloom.

\begin{tabular}{|c|c|c|c|c|c|c|c|c|c|}
\hline \multirow[b]{2}{*}{ Parameter } & \multirow[b]{2}{*}{ Estimate } & \multirow[b]{2}{*}{$\mathrm{SE}$} & \multirow[b]{2}{*}{$\begin{array}{c}95 \% \text { Confidence } \\
\text { intervals }\end{array}$} & \multirow[b]{2}{*}{$\mathrm{R}^{2}$} & \multicolumn{5}{|c|}{ ANOVA } \\
\hline & & & & & Source & $\mathrm{df}$ & $\begin{array}{l}\text { Sum of } \\
\text { squares }\end{array}$ & $\begin{array}{c}\text { Mean } \\
\text { square }\end{array}$ & $P$ \\
\hline $\mathrm{B}_{1}$ & -3.2418 & 0.4696 & -4.1923 to -2.2912 & $0.936^{\mathrm{z}}$ & Regression & 4 & 174723 & 43931 & $<0.0001$ \\
\hline $\mathrm{B}_{2}$ & 0.0218 & 0.00435 & 0.0130 to 0.0306 & & Residual & 38 & 1888 & 49.68 & \\
\hline $\mathrm{B}_{3}$ & -0.0000452 & 0.000012 & -0.00007 to -0.00002 & & & & & & \\
\hline $\mathrm{B}_{4}$ & $3.446 \times 10^{-8}$ & $9.656 \times 10^{-9}$ & $1.511 \times 10^{-8}$ to $5.42 \times 10^{-8}$ & & & & & & \\
\hline
\end{tabular}


Table 5. Statistical differences between observed and predicted dates of sour cherry fruit diameter, expressed as percentage of final fruit size.

\begin{tabular}{lcccc}
\hline $\begin{array}{l}\text { Michigan } \\
\text { location }\end{array}$ & Year & $\begin{array}{c}\text { Observations } \\
\text { (no.) }\end{array}$ & $\begin{array}{c}\text { Mean } \\
\text { difference } \\
\text { (d) }\end{array}$ & $\begin{array}{c}\mathrm{MAE}^{z} \\
\text { (d) }\end{array}$ \\
\hline Clarksville & 1995 & 22 & -3 & 4 \\
Eau Claire & 1995 & 21 & 0 & 2 \\
Belding & 2004 & 10 & 0 & 3 \\
\hline
\end{tabular}

${ }^{2}$ Mean absolute error (MAE) is defined as the difference between the absolute value of predicted minus observed.

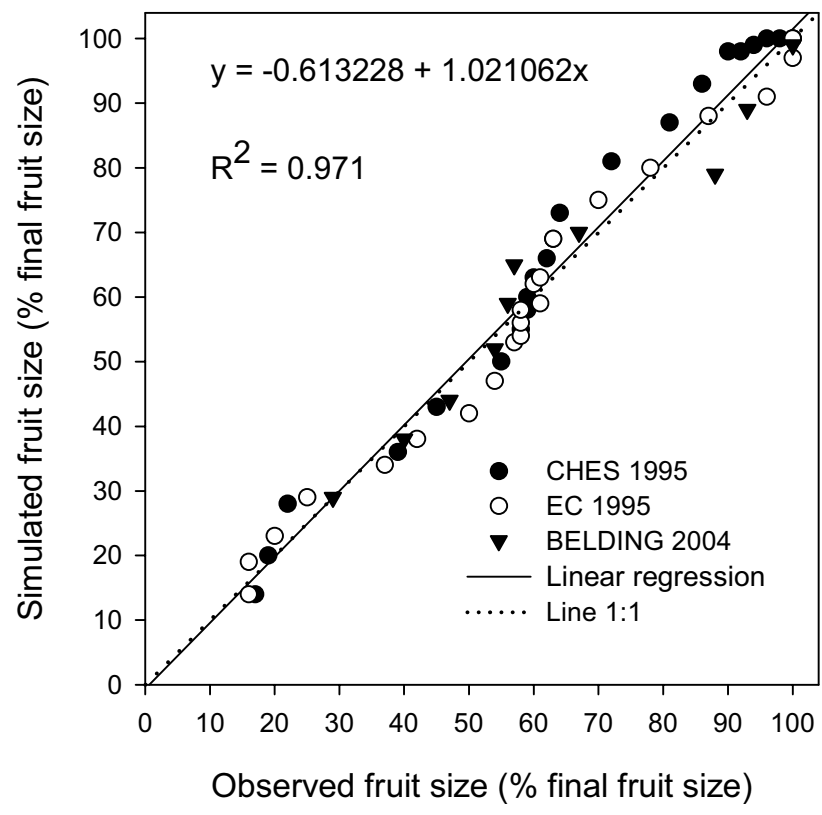

Fig. 5. Model simulated vs. observed fruit size expressed as percentage of final fruit size of sour cherry. Fruit diameter data were collected from the following location in Michigan: Clarksville (CHES 1995), Eau Claire (EC 1995), and Belding (BELDING 2004). On the graph, each point represents the percentage of fruit size relative to final size of observed/simulated fruit diameter at a given date of measurement.

Regardless, more information is needed in order to simulate the end of the rest period. Prediction of end of dormancy could reduce the observed variability at the early stages of flower bud development [stages near 50 GDD (Fig. 2)] by improving the accuracy of the prediction of the current flower bud, and overcome the potential problem of bud development earlier than 1 Mar., the starting date for GDD accumulation for side green in the proposed model. While the estimated bud phenological model is based on empirical relationships derived with Great Lakes region observations, the model proposed here should still be applicable in other regions, given that end of dormancy could be predicted or a representative date of end of dormancy could be determined.

Fruit diameter is a very important index of fruit growth and development and strongly related to the final yield (Orlandini et al., 1999). The sensitivity analysis performed on the fruit growth model, developed with observation from the three major sour cherry growing regions, confirmed the accuracy of the model presented and the good correlation between GDD and stage of fruit development. This model could be used to more effectively predict harvest date and therefore improve the timing of critical cultural practices related to stage of fruit development (i.e., the application of ethephon to favor fruit abscission for mechanical harvest).

From the plot of observed vs. simulated percentage of final fruit size (Fig. 5), a slight departure of the data from the line 1:1 when fruit development reached $60 \%$ to $100 \%$ of final size is evident. During the final stage of fruit development (Stage III), other factors besides temperature play a role in determining the final size. The length of the period of rapid growth and enlargement and final fruit size is also dependent on water availability (e.g., Hsiao, 1973), the leaf to fruit ratio (e.g., Flore, 1994), and the amount of light intercepted by leaves (e.g., Genard et al., 1999). Training system, pruning, and thinning are other important managerial aspects and have direct effect on fruit quality and size since they determine the amount of carbon supplied to the fruit through their effect on the leaf to fruit ratio (Genard et al., 1999).

The stages of sour cherry fruit size development are also influenced by the different ripening periods of the cultivar considered. Tukey (1934) compared sour cherry cultivars with different dates of fruit ripening in terms of the duration of Stages I, II, and III of fruit development. Duration of Stage I and the time of the initiation of Stage II were nearly identical in all cultivars, while the duration of Stage II was correlated to the date of fruit ripening, with shortest period of Stage II in earliest ripening cultivar. Given that only 'Montmorency' was considered in the development and testing of the fruit growth model presented here, further studies are needed to evaluate possible difference with cultivars with different ripening dates.

\section{Literature Cited}

Anderson, J.L., E.A. Richardson, and C.D. Kesner. 1986. Validation of chill unit and flower bud phenology models for 'Montmorency' sour cherry. Acta Hort. 184:71-78.

Andresen, J.A. and J.R. Harman. 1994. Springtime freezes in western lower Michigan: Climatology and trends. Michigan State Univ. Agr. Expt. Sta., Res. Rpt. 536, East Lansing.

Baskerville, G.L. and P. Emin. 1969. Rapid estimation of heat accumulation from maximum and minimum temperatures. Ecology 50:514-517.

Chmielewski, F.-M. 2003. Phenology and agriculture, p. 505-522. In: M.D. Schwartz(ed.). Phenology: An integrative environmental science. Kluwer Academic Publ., Dordrecht, The Netherlands.

Degrandi-Hoffman, G., R. Thorp, G. Loper, and D. Eisikowitch. 1996. Describing the progression of almond bloom using accumulated heat units. J. Appl. Ecol. 33:812-818.

DeJong, T.M. and J. Goudriaan. 1989. Modeling peach fruit growth and carbohydrate requirements: Reevaluation of the double-sigmoid growth pattern. J. Amer. Soc. Hort. Sci. 114:800-804.

Dennis, F.G. and G.S. Howell. 1974. Cold hardiness of tart cherry bark and flower buds. Michigan State Univ., Agr. Expt. Sta., Res. Rpt. 220, East Lansing.

Edson, C.E. 1986. An apple phenology study: Design of a predictive model of shoot growth, flower development and fruit growth. M.S. Thesis, Michigan State Univ., East Lansing.

Eisensmith, S.P., A.L. Jones, and J.A. Flore. 1980. Predicting leaf emergence of 'Montmorency' sour cherry from degree-day accumulation. J. Amer. Soc. Hort. Sci. 105:75-78. 
Eisensmith, S.P., A.L. Jones, E.D. Goodman, and J.A. Flore. 1982. Predicting leaf expansion of 'Montmorency' sour cherry from degree-day accumulations. J. Amer. Soc. Hort. Sci. 107:717-722.

Flore, J.A. 1994. Stone fruit, p. 233-270. In: B. Schaffer and P.C. Andersen (eds.). Handbook of environmental physiology of fruit crops. Vol. 1: Temperate crops. CRC Press, Boca Raton, Fla.

Gage, S.H., M.E. Whalon, and D.J. Miller. 1982. Pest event scheduling system for biological monitoring and pest management. Environ. Entomol. 11:1127-1133.

Genard, M. and C. Bruchou. 1993. A functional and exploratory approach to studying growth: The example of the peach fruit. J. Amer. Soc. Hort. Sci. 118:317-323.

Genard, M., F. Lescourret, and M. Ben Mimoun. 1999. Simulation of the effect of fruit thinning on peach quality. Acta Hort. 499:61-68.

Hsiao, T.C. 1973. Plant responses to water stress. Annu. Rev. Plant Physiol. 24:519-570.

Kvålseth, T.O. 1985. Cautionary note about R². Amer. Stat. 39:279_ 285.

Lakso, A.N., L. Corelli-Grappadelli, J. Barnard, and M.C. Goffinet. 1995. An expolinear model of the growth pattern of the apple fruit. J. Hort. Sci. 70:389-394.

Lang, G.A., J.D. Early, G.C. Martin, and R.L. Darnell. 1987. Endo-, para-, and ecodormancy: Physiological terminology and classification for dormancy research. HortScience 22:175-180.

Menzel, A. 2003. Plant phenological "fingerprints," p. 319-329. In: M.D. Schwartz(ed.). Phenology:An integrative environmental science, Kluwer Academic Publ., Dordrecht, The Netherlands.
Michigan Automated Weather Network. 2005. Automated weather station data for period of record using 'Data on Demand' feature. 31 July 2005. <http://www.agweather.geo.msu.edu/mawn/>.

Michigan Department of Agriculture. 2005. Michigan rotational survey: Fruit inventory 2003-2004. 13 Sept. 2005. <http://www.nass.usda. gov/mi/mi_fruit04/fruit.html>.

National Agricultural Statistic Service. 2005. Michigan statistical information. 13 Sept. 2005. <http://www.nass.usda.gov/mi/>.

National Oceanic and Atmospheric Administration. 2004. Cooperative summary of the day TD3200, 1984-2004. Natl. Climatic Data Ctr., Asheville, N.C.

Orlandini, S., P. Cappellini, M. Moriondo, and P. Ferrari. 1999. Analysis and modelling of apple fruit growth. Acta Hort. 499:137-143.

Richardson, E.A., S.D. Seeley, and D.R. Walker. 1974. A model for estimating the completition of rest for 'Redhaven' and 'Elberta' peach trees. HortScience 9:331-332.

Richardson, E.A., S.D. Seeley, D.R. Walker, J.L. Anderson, and G.L. Ashcroft. 1975. Pheno-climatology of spring peach bud development. HortScience 10:236-237.

Smith, R. 1985. Predicting the dates of first commercial harvest of selected Ontario peach cultivars. J. Amer. Soc. Hort. Sci. 110:650-654.

Tukey, H.B. 1934. Growth of the embryo, seed, and pericarp of the sour cherry (Prunus cerasus) in relation to season of fruit ripening. Proc. Amer. Soc. Hort. Sci. 31:125-144.

Weinberger, J.H. 1967. Some temperature relations in natural breaking of the rest of peach flower buds in the San Joaquin Valley, California. Proc. Amer. Soc. Hort. Sci. 91:84-89. 